\title{
BMJ Open Returning to daily life: a qualitative interview study on parents of childhood cancer survivors in Germany
}

\author{
Mona L Peikert (1D , ${ }^{1}$ Laura Inhestern (D) , ${ }^{1}$ Konstantin A Krauth, ${ }^{2}$ \\ Gabriele Escherich, ${ }^{3}$ Stefan Rutkowski, ${ }^{3}$ Daniela Kandels, ${ }^{4}$ Corinna Bergelt ${ }^{1}$
}

To cite: Peikert ML, Inhestern L, Krauth KA, et al. Returning to daily life: a qualitative interview study on parents of childhood cancer survivors in Germany. BMJ Open 2020;10:e033730. doi:10.1136/ bmjopen-2019-033730

- Prepublication history and additional material for this paper are available online. To view these files, please visit the journal online (http://dx.doi. org/10.1136/bmjopen-2019033730).

Received 20 August 2019 Revised 17 December 2019 Accepted 08 January 2020

Check for updates

(c) Author(s) (or their employer(s)) 2020. Re-use permitted under CC BY-NC. No commercial re-use. See rights and permissions. Published by BMJ.

${ }^{1}$ Department of Medical Psychology, University Medical Center Hamburg-Eppendorf, Hamburg, Germany

${ }^{2}$ Department of Pediatrics,

Pediatric Hematology \& Oncology, Klinik Bad Oexen, Bad Oeynhausen, North RhineWestphalia, Germany ${ }^{3}$ Clinic of Pediatric Hematology and Oncology, University Medical Center HamburgEppendorf, Hamburg, Germany

${ }^{4}$ Swabian Children's Cancer

Center, University Hospital

Augsburg, Augsburg, Bavaria, Germany

Correspondence to

Ms Mona L Peikert;

m.peikert@uke.de

\section{ABSTRACT}

Objectives To investigate experiences of parents of paediatric cancer survivors in cancer-related changes in the parents' daily life (work life, family life, partner relationship and social life) during and after intensive cancer treatment and to examine the reintegration process with its impeding and facilitating factors.

Design The design of this cross-sectional study involves a qualitative content analysis of semistructured interviews. Setting Participants were consecutively recruited in clinical settings throughout Germany.

Participants Forty-nine parents (59\% female) of 31 cancer survivors (aged $0-17$ at diagnosis of leukaemia or central nervous system tumour) were interviewed approximately 16-24 months after the end of intensive cancer treatment (eg, chemotherapy).

Results During treatment, more than $70 \%$ of parents reported difficulties reconciling paid work, household and family responsibilities and caring for the ill child. Couples spent little time with each other and approximately $25 \%$ reported dispute and burden. Many parents did not have enough energy for pursuing any hobbies during treatment. However, over the long term, being faced with the child's disease also led to strengthened relationships, new priorities, improved communication, increased mutual trust and greater appreciation for daily life. Supportive social networks (family/friends/employers), a strong partner relationship prior to the diagnosis and the use of psychosocial services (eg, family-oriented rehabilitation) had a positive impact. At the time of the interview, most families had adapted well. However, reintegration took time and some parents lacked the energy required to continue life as they did before the diagnosis.

Conclusions Even though most parents successfully readjusted to a new 'normality', reintegrating into daily life after paediatric cancer treatment remains difficult. Professional psychosocial support could help families with the reintegration process. Lastly, clinical staff (eg, physicians, psychologists, social workers) should bear in mind that the burden of parents does not automatically end with the end of intensive cancer treatment.

\section{INTRODUCTION}

In 2017, more than 2200 children under 18 years of age were diagnosed with cancer in Germany. ${ }^{1}$ In the last decades, improved diagnostics and treatment methods have led to

\section{Strengths and limitations of this study}

- We interviewed parents of childhood cancer survivors throughout Germany and reached an adequate sample size, including both the mother's and the father's perspective.

- In this interview study, we identified specific strains and needs of parents of childhood cancer survivors. Thus, the results may help to develop or to optimise support services that help parents with the re-entry into 'normal' life after the end of cancer treatment.

- A selection bias, especially in regards to the level of education, employment status, relationship status, mental stability and sufficient German language skills, cannot be ruled out, since the consecutive sampling did not allow for a non-responder analysis.

- It is possible that the retrospective design of the study affected the parental report of their experiences during their child's cancer treatment.

increased survival rates from $65 \%$ in the 1980 s to approximately $80 \%$ nowadays, resulting in a growing population of childhood cancer survivors. ${ }^{2}$ Yet, the end of cancer treatment does not necessarily seem to determine the end of illness-related burden in parents of childhood cancer survivors. ${ }^{3} 4$ Even years after diagnosis, some parents report clinically relevant mental distress levels. ${ }^{4}$ However, childhood cancer can also result in positive changes in parents (eg, appreciation of life), often described as 'post-traumatic growth'. ${ }^{67}$

Following the diagnosis of childhood cancer, some parents reduce their work time, take sick leave or even resign or lose their jobs to care for the paediatric patient and for the patient's siblings. ${ }^{8-10}$ Mothers seem to be more likely to reduce working hours or to stop working. ${ }^{10-12}$ These changes can also lead to financial problems after the child's diagnosis. ${ }^{10}$ Years after treatment, several parents still work less than before the cancer diagnosis. ${ }^{12-14}$ Family life can be negatively affected as well, for example, due to separation during hospital stays or less attention for 
healthy siblings. ${ }^{9131516}$ Family members have to adapt to new roles and responsibilities after the diagnosis. ${ }^{15}$ In the long term, families also report positive changes in family life, especially with regard to family closeness, cohesion and appreciation. $.^{9} 131517-19$ Notably, many parents focus on the family and the family home rather than pursuing social activities, which might lead to social isolation during cancer treatment and after. Study results reveal that the child's cancer disease can also affect the partner relationship. Some parents experienced more closeness in their relationship, ${ }^{15} 19$ while others reported marital tensions and in some cases separation. ${ }^{91519}$ According to a recent systematic review, most couples successfully master the crisis of childhood cancer. ${ }^{20}$

In conclusion, the literature shows that childhood cancer and its treatment lead to long-term changes in the lives of parents of paediatric cancer survivors. ${ }^{2122}$ The transition back to normality after the end of treatment is often a major challenge and thus requires intensive psychosocial aftercare for the entire family. Hence, the familyoriented rehabilitation programme (FOR), a 4-week inpatient rehabilitation concept in Germany, routinely includes all family members. ${ }^{23}{ }^{24}$ Previous research mostly focused on the time from the diagnosis to the end of the cancer treatment. Many studies included a broad, heterogeneous sample of parents regarding the time since diagnosis. Not much is known about reintegration processes of parents into daily life directly after the end of the treatment. In this interview study, we have investigated parental experiences in cancer-related changes in their daily life during and in particular after intensive cancer treatment. Furthermore, we have examined the reintegration process together with the impeding as well as facilitating factors. We interviewed parents of survivors of leukaemia or central nervous system (CNS) tumour, the most frequent childhood cancers in Germany, ${ }^{1}$ approximately 16-24 months after the end of intensive cancer treatment to answer the following questions:

1. Which cancer-related changes in their daily life (work, family life, partner relationship and social life) do parents of childhood cancer survivors experience during intensive cancer treatment and thereafter?

2. Which factors impede or facilitate reintegration into daily life after end of treatment? How do rehabilitation programmes influence reintegration and psychosocial outcomes?

3. How do parents experience the reintegration process and how do they feel about their current situation?

\section{METHODS AND ANALYSIS}

\section{Design}

This qualitative interview study is part of a prospective observational study with a longitudinal mixed-methods design. ${ }^{25}$ The study protocol was published elsewhere. ${ }^{25}$ In this interview study, we investigated the reintegration process of parents and children. The following analyses focus on the parents' daily life. The interview guideline is provided in online supplementary appendix A. The reporting of this article follows the Consolidated Criteria for Reporting Qualitative Research. ${ }^{26}$

\section{Participants}

Inclusion and exclusion criteria

Interviews were conducted with parents or other caregivers approximately 16-24 months after the end of their child's intensive cancer treatment. The children were up to the age of 17 at the time of their diagnosis (leukaemia or CNS tumour). Exclusion criteria constituted refusal of participation, serious physical and/or mental burden (applicable if the interview would be unduly burdensome), cognitive limitations and insufficient German language skills. Inclusion and exclusion criteria were assessed by the study registries and the healthcare providers in the clinics.

\section{Sampling and sample size}

Parents were recruited via two different approaches. First, we recruited parents who had already participated in the quantitative part of our prospective observational study. ${ }^{25}$ Families received information letters and consent forms to participate in an interview with the final set of questionnaires. Second, we recruited families via the International HIT-MED Registry (I-HIT-MED; ClinicalTrials. gov Identifier: NCT02417324) and the Cooperative Study Group for Childhood Acute Lymphoblastic Leukemia (COALL) study (COALL 08-09; ClinicalTrials. gov Identifier: NCT01228331). They identified potentially eligible patients who received aftercare at the same site as the research institute. When attending their next follow-up appointment, the physician informed the parents about the study and gave them written information and consent forms. We approached a consecutive sample of the first 25 families that agreed to participate in the interview study and continued recruiting until no new themes occurred in the interviews and until data saturation was reached. ${ }^{27}$

\section{Data collection and analysis}

Research team and reflexivity

The authors MLP and LI conducted the interviews. Both interviewers are female researchers, graduated psychologists and experienced in conducting qualitative studies.

\section{Procedure}

We conducted semistructured qualitative telephone interviews with one interviewer and one interviewed parent. Face-to-face interviews were offered to participants from the Hamburg region. In the beginning, the interviewer provided background information on the research project, data protection and organisational matters. We also assessed sociodemographic and medical characteristics. The interview guideline was pilot tested in the first interview and was only slightly adapted afterwards. Hence, we included the pilot interview in the data analyses. At the end of the semistructured interview, the parents were encouraged to add further experiences or thoughts. Field notes were taken during and after the interview. 


\section{Data analysis}

The audio files were transcripted verbatim using the Simple transcription system ${ }^{28}$ and the f4transkript software V.4.2 (www.audiotranskription.de). The transcripts were not returned to the parents for comments or corrections. The interviews were analysed using the methodical approach of qualitative content analysis. ${ }^{29}$ MLP and LI generated categories both deductively (based on the interview guideline and on theoretical considerations) and inductively (from the transcripts) using the qualitative data analysis software MAXQDA V.10. A coding guideline with all category labels, category definitions, necessary coding rules and anchor samples is provided in online supplementary appendix B. MLP coded all interviews with this coding system and LI coded 20 interviews to enhance reliability. The intercoder agreement was $85 \%$. Interviews of mothers and fathers of the same child were analysed separately. Sociodemographic and medical characteristics were analysed descriptively with the software IBM SPSS Statistics V.25. Additionally, we conducted an exploratory subgroup analysis on differences between the experiences of parents of CNS tumour and leukaemia survivors. We compared the codings in every category systematically between the diagnosis groups.

\section{Patient and public involvement}

Childhood cancer patients and their families were involved in our research project by participating in our pilot study. ${ }^{3031}$ The results of the pilot study had a crucial impact on our choice of research questions, outcome measures and instruments for this prospective observational study. Furthermore, the participants of the pilot study were asked to provide information on missing topics and to add further considerations that were implemented in our interview guideline.

\section{RESULTS}

We have reported our results under four main areas of daily life: Work life, family life, partner relationship and social life. Within each area we have specified changes, barriers and facilitators (including the impact of rehabilitation measures) as well as the reintegration process and satisfaction with current daily life.

\section{Sample characteristics}

Information letters were sent to 113 families that had participated in the quantitative study. ${ }^{25}$ Further information letters were issued by the cooperating study centres. The number of informed parents in this second recruitment approach is unclear. In total, 35 families returned the signed consent form. Interviews were conducted with 29 mothers and 20 fathers from 31 families. Parents from four families had dropped out due to incomplete contact data $(n=1)$ or because no interview appointment could be arranged $(n=3)$. One interview was conducted face to face. The average interview length was $43 \mathrm{~min}$ (range: $20-112 \mathrm{~min}$ ). Tables 1 and 2 provide an overview of the sociodemographic and medical data of parents and patients.
Work life

Changes

In more than half of the families, the child's disease led to sick leave for at least one parent during treatment. Thirtyfive per cent of the parents reduced their working hours, terminated their job or chose a career change with better working conditions. Two parents lost their jobs.

I was fired because my bosses weren't really patient anymore because, well, the sickness is lasting so long and for a long time I have been just not as resilient as others. (Father of a toddler)

Furthermore, many parents described that the family took priority over work and that they handled difficulties at work more calmly. While more than $20 \%$ of the parents reported that working gave them a sense of normality, others reported lower productivity and loss of concentration.

I'm not that tough anymore. I have to save my energy. Therefore, you have to slow down a bit with regard to your career. (Mother of a school-aged child)

Four parents also reported financial difficulties.

\section{Barriers and facilitators}

The most important facilitating factors for parents' work life were support by the extended family and friends as well as support by employers.

My parents, who are both retired, live really close to us, just around the corner. And without them I wouldn't be able to be back at work again. (Mother of a school-aged child)

More than $40 \%$ of the parents that participated in a FOR reported that the programme had helped them to acquire greater resilience and energy. Other reported positive factors encompassed flexible working hours, support by the health insurance (eg, nursing service), maternity/paternity leave or being a homemaker as well as self-employment. Negative factors that influenced work life included a young age of the children, shift work and a long commuting distance.

\section{Reintegration process and current daily life}

For many parents, the occupational reintegration gradually took place after the end of the intensive cancer treatment or after a FOR. Fifteen per cent of the employed fathers and $91 \%$ of the employed mothers were working part time at the time of the interview. Only one mother was seeking employment. Most parents expressed a rather positive attitude towards their current work situation. Many parents appreciated flexible working hours and part-time work, because the child that was diagnosed with cancer still required extra care and follow-up visits in the clinic.

My priorities are definitely private. [...] I went down to 30 hours because I just hadn't had the time at 
Table 1 Sociodemographic data of 49 parents from 31 families

\begin{tabular}{|c|c|c|c|c|c|c|}
\hline \multirow[b]{2}{*}{ Sociodemographic data (parents) } & \multicolumn{2}{|c|}{ Total $(n=49)$} & \multicolumn{2}{|c|}{ Fathers $(n=20)$} & \multicolumn{2}{|c|}{ Mothers $(n=29)$} \\
\hline & n & $\%$ & $\mathbf{n}$ & $\%$ & n & $\%$ \\
\hline Age in years (mean, SD/range) & 42.6 & $\begin{array}{l}7.1 / \\
26-65\end{array}$ & 43.4 & $\begin{array}{l}5.9 / \\
31-52\end{array}$ & 42.0 & $\begin{array}{l}7.9 / \\
26-65\end{array}$ \\
\hline \multicolumn{7}{|l|}{ Familial situation } \\
\hline Permanent relationship* & 44 & 91.7 & 18 & 94.7 & 26 & 89.7 \\
\hline Living with the partner* & 43 & 90.0 & 18 & 94.7 & 25 & 86.2 \\
\hline \multicolumn{7}{|l|}{ Family living situation* } \\
\hline Living with the other parent and the child/children & 42 & 87.5 & 18 & 94.7 & 24 & 82.8 \\
\hline Living only with the child/children & 5 & 10.4 & 1 & 5.3 & 4 & 13.8 \\
\hline Patchwork family & 1 & 2.1 & 0 & 0 & 1 & 3.5 \\
\hline \multicolumn{7}{|l|}{ Education } \\
\hline$>10$ years & 34 & 69.4 & 14 & 70.0 & 20 & 69.0 \\
\hline$\leq 10$ years & 15 & 30.6 & 6 & 30.0 & 9 & 31.0 \\
\hline \multicolumn{7}{|l|}{ Employment status } \\
\hline Gainfully employed & 42 & 85.7 & 20 & 100 & 22 & 75.9 \\
\hline Full time & 19 & 45.2 & 17 & 85.0 & 2 & 9.1 \\
\hline Part time & 23 & 54.8 & 3 & 15.0 & 20 & 90.9 \\
\hline Not gainfully employed & 7 & 14.3 & 0 & 0 & 7 & 24.1 \\
\hline Homemakers & 3 & 42.9 & 0 & 0 & 3 & 42.9 \\
\hline Maternity/paternity leave & 3 & 42.9 & 0 & 0 & 3 & 42.9 \\
\hline Seeking employment & 1 & 14.3 & 0 & 0 & 1 & 14.3 \\
\hline \multicolumn{7}{|l|}{ Child's cancer diagnosis } \\
\hline CNS tumour & 15 & 30.6 & 6 & 30.0 & 9 & 31.0 \\
\hline Leukaemia & 34 & 69.4 & 14 & 70.0 & 20 & 69.0 \\
\hline
\end{tabular}

${ }^{*}$ Missing value of one father.

CNS, central nervous system.

home. And that's more important to me. (Father of a toddler)

\section{Family life \\ Changes}

Especially during the inpatient cancer treatment, more than $70 \%$ of the parents struggled with the difficulties of dealing with everyday life (eg, work, household, disease management, childcare). Almost one-third of the parents reported that a new allocation of responsibilities became necessary.

We had to organise ourselves even more. Who takes care when and for which child, who goes to the hospital, who goes to work? Without the support of our social network, grandparents, friends and so on we wouldn't have managed the situation. (Mother of a school-aged child)

Sixteen of 26 families with more than one child reported that siblings received less attention from their parents, which made many parents feel guilty.
You always can intend not to forget your second child in such situations but it's hard to put into practice, because even if you're playing with your second child while the other child is in hospital, you always have something on your mind. [...] Then you hear about other mothers, who are in the same situation. Sitting in bed at nighttime crying and don't know how to fix it. (Mother of a toddler)

However, many parents also mentioned positive changes, such as strengthened family relationships and a shift of priorities towards the family being most important.

\section{Barriers and facilitators}

Support by the extended family, especially the grandparents, and friends was an important resource (eg, childcare, grocery shopping).

My husband had to go to work, I was in the hospital and grandma did everything she could to make sure the children were cared for. (Mother of a school-aged child) 
Table 2 Sociodemographic and medical data of the 31 paediatric cancer patients

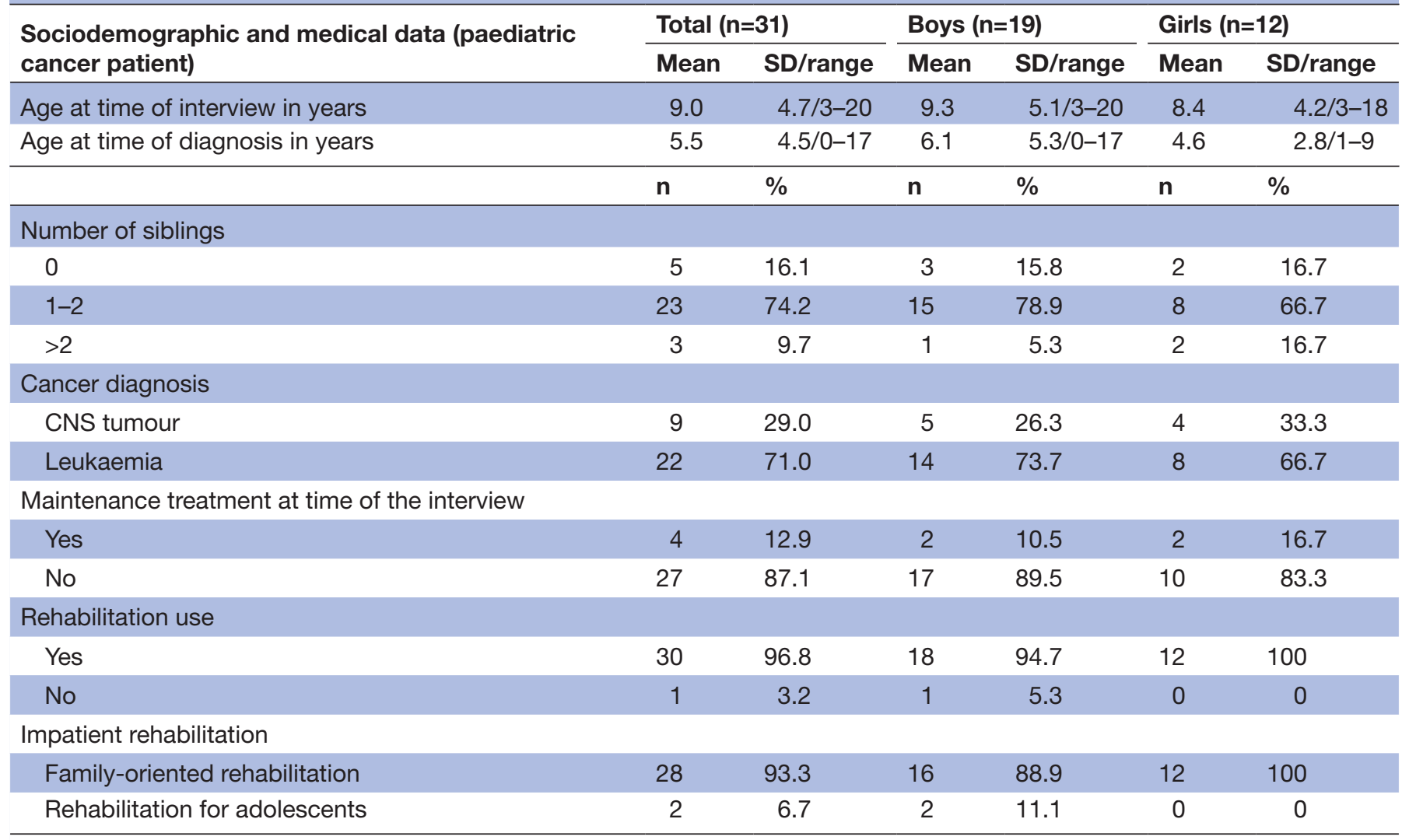

CNS, central nervous system.

Twenty-two of 28 families that participated in a FOR described a positive influence of the programme on their family life (eg, spending time together, coping with family problems). Other factors that affected family life positively were the siblings, the use of other psychosocial support services, a clinic in near vicinity and financial security. However, parental fear of progression impeded a carefree, 'normal' family life.

You don't have cancer and then at some point you are healthy again and everything is good. I think it's just a very formative experience you can only process it but you can't just shake it off. And it also shapes the whole environment somehow. [...] That is very formative, also for families. (Mother of a toddler)

So the point is, you're always afraid there's going to be something like that again and the fear pops up with every small matter. In these cases, rational mechanisms fail. So that's affecting me quite a lot now. (Mother of a school-aged child)

Furthermore, parents reported that additional burden such as house construction, physical impairment of the survivor, risk of infection and further medical issues in the family impaired family life.

Reintegration process and current daily life

After the end of the intensive cancer treatment, some families still had to deal with physical or psychosocial long-term consequences of the disease that affected their family life negatively. However, at the time of the interview, many parents pointed out positive aspects of current family life (eg, greater appreciation of daily life).

Looking back, I would say our family life became even better. We came closer together. (Mother of a school-aged child)

\section{Partner relationship Changes}

Approximately $40 \%$ of the parents described positive changes in their relationship such as improved communication, increased trust and a strengthened bond. However, approximately half of the parents also stated negative changes. During the intensive cancer treatment, the patient required 24 hours care and in many families, the parents only met in the clinic during certain treatment phases.

It has been a massive burden and we took turns looking after this child 24/7. So we weren't even husband and wife anymore. We basically saw each other when we handed over the child, where we talked about what has happened and so on. So when I was at home, my wife was at the hospital and when my wife was at home, I was at the hospital. (Father of a school-aged child) 
Dispute and burden during and after the treatment phase was mentioned by approximately one quarter of the parents. In one family, the parents separated during the treatment period.

\section{Barriers and facilitators}

Parents reported that the quality of the relationship prior to the diagnosis crucially influenced the relationship during and after treatment. Existing problems exacerbated, whereas a strong relationship served as a resource. Grandparents covering responsibilities in the childcare enabled parents to spend time together. Almost 30\% of the interviewed parents who had participated in a FOR described the programme as helpful for their relationship (eg, use of couple therapy during the FOR, discovering new hobbies together as a couple). The relationship was described as an enormous resource during and after cancer treatment by almost $70 \%$ of the parents who lived in a relationship.

I was somehow the tower of strength. When the recurrence came, all were in tears and somebody had to say "Everything will be alright" although you might also need mental support. But then you had to find the strength to console. (Father of a toddler)

Single parents lacked the mutual support by a partner.

You're lonely from time to time. Always to have to be self-motivated is kind of hard. I suppose it's easier together. (Mother of a school-aged child)

\section{Reintegration process and current daily life}

Even though the relationship of some parents remained strained, most couples reported to be satisfied with their relationship and spent time together in a more conscious and appreciative way. Looking ahead, they felt strengthened, since they went through the child's cancer treatment together.

I think our relationship has intensified. Together we have overcome a major crisis. This has strengthened our trust in each other and also the bond between us. (Father of a toddler)

\section{Social life}

\section{Changes}

Social isolation and withdrawal during their child's cancer treatment was reported by almost $30 \%$ of the parents. Reasons were for example, limited time or energy.

But there was no way to even think about having a hobby. There's no time for that at all. So if I pursued a hobby at that time, it was getting some sleep. [...] I'll just say, that was the only thing worth striving for. Giving your body a break to regain strength. (Mother of an adolescent child)

Few parents engaged in hobbies (eg, sports) for relaxation or distraction purposes during treatment. One quarter of the parents mentioned that friendships ended and one-third of the parents made new friends and deepened existing friendships.

We have fewer friends since then, but deeper and by far less superficial contacts. (Father of a toddler)

Around $65 \%$ of the parents described the contact to other affected parents who shared their situation as helpful. Some parents who lacked this contact, due to living far away from each other, wished for more exchange.

[...] where you don't have to restrict yourself while talking. Well, you can mention radiotherapy without shocking others. More like "Ok, well, how was it for you?". That is already a big relief. (Mother of a toddler)

\section{Barriers and facilitators}

More than $60 \%$ of the parents who participated in a FOR reported a positive impact on their social life (eg, getting in contact with other affected families, new input for leisure activities and self-care). Additionally, more than half of the parents reported support and understanding of family and friends as a facilitating factor. Single parents, shift workers and families with a physically burdened child struggled most with social activities since they only had little time available.

\section{Reintegration process and current daily life}

While some parents reintegrated quickly into their daily social life after the end of treatment, the reintegration process for others took months or years.

It took me a long time to have the energy to say 'I'm meeting someone now'. You have to become active again. I still suffer from chronic exhaustion in such things. (Mother of a school-aged child)

Step by step, most parents reintegrated into their social life and (re)gained the ability to self-care. However, when weighting up time with the family or time alone or with friends many parents focused more on the family than before the cancer diagnosis.

\section{Explorative subgroup analysis}

The results of our explorative subgroup analysis revealed only minor differences between parents of CNS tumour and leukaemia survivors: The risk of infection seems to be more restrictive in families of leukaemia survivors, especially with regard to family and social activities (eg, going swimming, having visitors).

\section{DISCUSSION}

In our interview study, parents of childhood cancer survivors reported various positive and negative cancer-related changes in their daily life. We also identified factors that impeded or facilitated reintegration retrospectively and investigated the parents' satisfaction with their current daily life. 


\section{Return to daily life}

In many cases, the childhood cancer disease caused long-term changes on the parents' work life, especially in mothers. Some parents did not return to work as they did before the disease, because the children still needed special support or because of new priorities. Parents benefited particularly from supportive employers and flexible working time models. Family friendly working environments are therefore especially important for parents of seriously ill children. ${ }^{14}$

The childhood cancer diagnosis affected the entire family system and led to various changes in daily family life. The most frequently reported changes were organisational challenges, new task allocations within the family and siblings drifting out of focus. Yet, positive changes were mentioned, such as a strengthened relationship and family resilience. At the time of the interview, parental fear of progression still burdened the family life of some parents.

Most parents adapted well to cancer-related changes in their partner relationship and reported a strengthened bond. A recent large-scale study which investigated the relationship status and quality of parents of long-term childhood cancer survivors found an increased dependency within the partner relationship in terms of solving problems together and having a particularly close relationship. ${ }^{32}$ Our qualitative results show that these effects already occur in an early stage of survivorship.

Even after the end of treatment, some parents remained in their family for the time being and reported a recovery time of several months until the strength and desire for social and leisure activities returned. Social isolation of parents of children with cancer during treatment has already been described in earlier studies. ${ }^{8} 13$ Our study shows that this social isolation can also last beyond the end of treatment.

\section{Clinical implications and future research}

Even though not every family requires psychosocial support measures, support should be offered to every family that needs or requests professional help even after the end of treatment. Various psychosocial interventions for parents or the entire family have been described in earlier studies. ${ }^{21}$ However, the concept of an inpatient family-oriented rehabilitation programme for the entire family is only implemented in Germany. ${ }^{21}$

When developing or optimising support services that help families with the re-entry into 'normal' life, fear of progression that impedes reintegration should be taken into account. ${ }^{33}$ Furthermore, healthcare providers should identify families with specific support needs (eg, single parents or families without support from the extended family). Although the results of our explorative subgroup analysis revealed only minor differences between parents of CNS tumour and leukaemia survivors, different diagnosis groups can have specific psychosocial burdens (eg, impaired social functioning in brain tumour survivors). ${ }^{34}$ A quantitative approach would allow for a systematic analysis of psychosocial differences between leukaemia and CNS tumour survivors and their family members.

Furthermore, little is known about the reintegration into social life of affected parents, even though social contacts, positive activities and self-care are important resources. Social life could be an important protective factor and should therefore be further investigated.

Due to the rarity of childhood cancer, parents in our study often reported lacking contact to other affected families near their home and wished for more exchange. Support groups that are not connected to a specific place of residence, such as computer-based support groups, ${ }^{35}$ are required.

\section{Conclusion}

Even though most families successfully (re)adjust to a new 'normality', (re)integrating into daily life after cancer treatment remains difficult. Professional psychosocial support can help families during treatment as well as thereafter. In our study, the FOR was considered particularly helpful. New programmes (eg, computermediated support groups, multimodal programmes) that help families with the reintegration into daily life should be developed and evaluated. Most importantly, healthcare professionals (eg, physicians, psychologists, social workers) should bear in mind that the burden of parents does not automatically end with the end of intensive cancer treatment.

Acknowledgements The authors gratefully thank all mothers and fathers who participated in this study. They also acknowledge their student assistants Johanna Dreyer, Rebecca-Miriam Haase, Anne Kleine Büning, Louisa Meerjanssen, Pia Struck and Ruth Wewers for their help.

Contributors $\mathrm{CB}$ is the principal investigator of the study. $\mathrm{CB}$ and $\mathrm{LI}$ developed the study concept and the design. LI and MLP developed the study materials and MLP, $\mathrm{LI}, \mathrm{KAK}, \mathrm{GE}, \mathrm{SR}$ and DK acquired the data. MLP and LI analysed and interpreted the data. MLP wrote the first draft of the manuscript. CB, LI, KAK, GE, SR, and DK revised the first draft critically for important intellectual content. All authors have revised the subsequent drafts critically, approved the final manuscript to be published and agreed to be accountable for all aspects of the work.

Funding This work was supported by the 'North Rhine-Westphalia Association for the Fight Against Cancer, Germany' (Arbeitsgemeinschaft für Krebsbekämpfung im Lande Nordrhein-Westfalen, ARGE). The ARGE is not involved in the study design, the collection, analysis and interpretation of data and in writing the manuscript.

Competing interests None declared.

Patient consent for publication Not required.

Ethics approval The study was approved by the Ethics Committee of the Medical Chamber of Hamburg (number: PV5277).

Provenance and peer review Not commissioned; externally peer reviewed.

Data availability statement All data relevant to the study are included in the article or uploaded as supplementary information. The interview transcripts are not available due to the sensitive and personal nature of the data.

Open access This is an open access article distributed in accordance with the Creative Commons Attribution Non Commercial (CC BY-NC 4.0) license, which permits others to distribute, remix, adapt, build upon this work non-commercially, and license their derivative works on different terms, provided the original work is properly cited, appropriate credit is given, any changes made indicated, and the use is non-commercial. See: http://creativecommons.org/licenses/by-nc/4.0/.

\section{ORCID iDs}

Mona L Peikert http://orcid.org/0000-0002-3754-7363

Laura Inhestern http://orcid.org/0000-0003-2513-7954 


\section{REFERENCES}

1 Kaatsch P, Grabow D, Spix C. German childhood cancer registry annual report 2018 (1980-2017). Institute of Medical Biostatistics, Epidemiology and Informatics (IMBEI) at the University Medical Center of the Johannes Gutenberg University Mainz, 2019.

2 Kaatsch P. Epidemiology of childhood cancer. Cancer Treat Rev 2010;36:277-85

3 Labay LE, Mayans S, Harris MB. Integrating the child into home and community following the completion of cancer treatment. $J$ Pediatr Oncol Nurs 2004;21:165-9.

4 Ljungman L, Cernvall M, Grönqvist H, et al. Long-term positive and negative psychological late effects for parents of childhood cancer survivors: a systematic review. PLoS One 2014;9:e103340.

5 Kazak AE, Alderfer M, Rourke MT, et al. Posttraumatic stress disorder (PTSD) and posttraumatic stress symptoms (PTSS) in families of adolescent childhood cancer survivors. J Pediatr Psychol 2004;29:211-9.

6 Barakat LP, Alderfer MA, Kazak AE. Posttraumatic growth in adolescent survivors of cancer and their mothers and fathers. $J$ Pediatr Psychol 2006;31:413-9.

7 Hungerbuehler I, Vollrath ME, Landolt MA. Posttraumatic growth in mothers and fathers of children with severe illnesses. $J$ Health Psychol 2011;16:1259-67.

8 Soanes L, Hargrave D, Smith L, et al. What are the experiences of the child with a brain tumour and their parents? Eur J Oncol Nurs 2009;13:255-61.

9 Sloper P. Needs and responses of parents following the diagnosis of childhood cancer. Child Care Health Dev 1996;22:187-202.

10 Roser K, Erdmann F, Michel G, et al. The impact of childhood cancer on parents' socio-economic situation-a systematic review. Psychooncology 2019;28:1207-26.

11 Lindahl Norberg A, Montgomery SM, Bottai M, et al. Short-term and long-term effects of childhood cancer on income from employment and employment status: a national cohort study in Sweden. Cancer 2017; 123:1238-48.

12 Mader L, Rueegg CS, Vetsch J, et al. Employment situation of parents of long-term childhood cancer survivors. PLoS One 2016;11:e0151966.

13 Lindahl Norberg A, Steneby S. Experiences of parents of children surviving brain tumour: a happy ending and a rough beginning. Eur $J$ Cancer Care 2009;18:371-80.

14 Wakefield CE, McLoone JK, Evans NT, et al. It's more than dollars and cents: the impact of childhood cancer on parents occupational and financial health. J Psychosoc Oncol 2014;32:602-21.

15 Long KA, Marsland AL. Family adjustment to childhood cancer: a systematic review. Clin Child Fam Psychol Rev 2011;14:57-88.

16 West $\mathrm{CH}$, Bell JM, Woodgate RL, et al. Waiting to return to normal: an exploration of family systems intervention in childhood cancer. $J$ Fam Nurs 2015;21:261-94.

17 Williams LK, McCarthy MC, Eyles DJ, et al. Parenting a child with cancer: perceptions of adolescents and parents of adolescents and younger children following completion of childhood cancer treatment. J Fam Stud 2013;19:80-9.

18 Van Schoors M, Caes L, Verhofstadt LL, et al. Systematic review: family resilience after pediatric cancer diagnosis. J Pediatr Psychol 2015;40:856-68.
19 Quin S. The long-term psychosocial effects of cancer diagnosis and treatment on children and their families. Soc Work Health Care 2005;39:129-49.

20 Van Schoors M, Caes L, Alderfer MA, et al. Couple functioning after pediatric cancer diagnosis: a systematic review. Psychooncology 2017;26:608-16.

21 Peikert ML, Inhestern L, Bergelt C. Psychosocial interventions for rehabilitation and reintegration into daily life of pediatric cancer survivors and their families: a systematic review. PLoS One 2018;13:e0196151.

22 Wakefield CE, McLoone J, Butow P, et al. Support after the completion of cancer treatment: perspectives of Australian adolescents and their families. Eur J Cancer Care 2013;22:530-9.

23 Arbeitsgemeinschaft Familienorientierte Rehabilitation (AGFOR). Positionspapier zur familienorientierten Rehabilitation bei krebskranken Kindern, 2001. Available: https://www.kinderkrebsinfo. de/fachinformationen/psapoh/rehabilitation/index_ger.html [Accessed Apr 2017].

24 Schröder HM, Lilienthal S, Schreiber-Gollwitzer BM, et al. Psychosoziale Versorgung in der pädiatrischen Onkologie und Hämatologie, 2013. Available: http://www.awmf.org/leitlinien/detail/ll/ 025-002.html [Accessed Apr 2017].

25 Peikert ML, Inhestern L, Bergelt C. The role of rehabilitation measures in reintegration of children with brain tumours or leukaemia and their families after completion of cancer treatment: a study protocol. BMJ Open 2017;7:e014505.

26 Tong A, Sainsbury P, Craig J. Consolidated criteria for reporting qualitative research (COREQ): a 32-item checklist for interviews and focus groups. Int J Qual Health Care 2007;19:349-57.

27 Bowen GA. Naturalistic inquiry and the saturation concept: a research note. Qual Res 2008;8:137-52.

28 Dresing T, Pehl T. Praxisbuch Interview, Transkription \& Analyse. In: Anleitungen und Regelsysteme für qualitativ Forschende. 6th edn. Marburg, 2016.

29 Mayring P. Qualitative content analysis: theoretical foundation, basic procedures and software solution, 2014. Available: https://www. ssoar.info/ssoar/handle/document/39517 [Accessed Aug 2018]

30 Inhestern L, Beierlein V, Krauth KA, et al. Belastungen und RehaZiele von Familien in der pädiatrisch-onkologischen Rehabilitation [Burden and rehabilitation goals of families in pediatric-oncological rehabilitation]. Prax Kinderpsychol Kinderpsychiatr 2017;66:194-208.

31 Inhestern L, Beierlein V, Krauth KA, et al. Belastungen bei Eltern krebskranker Kinder in der familienorientierten Rehabilitation [Burden of parents of pediatric cancer patients in pediatric-oncological rehabilitation]. Prax Kinderpsychol Kinderpsychiatr 2017;66:179-93.

32 Mader L, Roser K, Baenziger J, et al. Relationship status and quality of the partner relationship in parents of long-term childhood cancer survivors: the Swiss childhood cancer Survivor Study-Parents. Psychooncology 2019;28:309-16.

33 Clever K, Schepper F, Pletschko T, et al. Psychometric properties of the fear of progression questionnaire for parents of children with cancer (FoP-Q-SF/PR). J Psychosom Res 2018;107:7-13.

34 Wilford J, Buchbinder D, Fortier MA, et al. "She was a little social butterfly": a qualitative analysis of parent perception of social functioning in adolescent and young adult brain tumor survivors. $J$ Pediatr Oncol Nurs 2017;34:239-49.

35 Bragadóttir $\mathrm{H}$. Computer-mediated support group intervention for parents. J Nurs Scholarsh 2008;40:32-8. 